\title{
La demanda de trabajadores huéspedes en la agricultura estadounidense*
}

Simón-Pedro Izcara-Palacios **

Recibido: 20I2-09-20 Aprobado: 20I3-06-I5 Disponible en línea: 20I4-05-30

doi:I0.III44/Javeriana.CDRII-73.dtha

Cómo citar este artículo: Izcara-Palacios, S. P. (2014). La demanda de trabajadores huéspedes en la agricultura estadounidense. Cuadernos de desarrollo rural, II(73), I49-169. doi:I0.III44/Javeriana.CDRII-73.dtha

\section{Resumen}

Este artículo tiene como objetivo examinar por qué se ha incrementado la demanda de trabajadores huéspedes en el sector agrario estadounidense, en un contexto de crisis económica y elevadas tasas de desempleo. Se utilizó una metodología cualitativa que incluyó la realización, entre 2008 y 2012, de entrevistas en profundidad a 60 contrabandistas de migrantes mexicanos, empleados por empresarios agrarios estadounidenses que demandaban trabajadores huéspedes y mano de obra indocumentada. El resultado más relevante de esta investigación es que la demanda de trabajadores huéspedes aparece subordinada a la disponibilidad de indocumentados. Muchos empleadores contratan trabajadores huéspedes, bien porque no disponen de suficientes jornaleros indocumentados, o bien para justificar el empleo de mano de obra ilegal.

\section{Palabras clave:}

visas $\mathrm{H}-2 \mathrm{~A}$; agricultura; trabajadores huéspedes; jornaleros indocumentados; Estados Unidos

\section{Palabras clave descriptores:}

extranjeros ilegales; trabajadores agrícolas migratorios; Estados Unidos

\footnotetext{
* Este artículo es producto del proyecto de investigación titulado Migrantes rurales tamaulipecos y el programa H-2A de trabajadores buéspedes. Convenio número: UAT-07-8-SOC-oIr4, y del proyecto SEP/Conacyt I5590I, titulado Coyotaje y migración indocumentada en Tamaulipas.

** Doctor en Sociología por la Universidad Complutense de Madrid, y profesor de Sociología Rural en la Unidad Académica Multidisciplinaria de Ciencias, Educación y Humanidades (Universidad Autónoma de Tamaulipas, México), también es miembro del Sistema Nacional de Investigadores de México (Nivel II). Su área de especialización son los estudios rurales. Correo electrónico: sizcara@uat.edu.mx
} 


\title{
The Demand for Guest Workers in the U.S. Agriculture
}

\begin{abstract}
This article aims to examine why the demand for guest workers in the U.S. agricultural sector has increased in a context of economic crisis and high unemployment rates. A qualitative methodology was implemented. It included interviewing 60 Mexican migrant smugglers between 2008 and 20I2. The migrants were hired by North American agricultural employers that demanded guests workers and undocumented workforce. The most important result of this research is that the guest workers demand appears to be subordinated to the availability of undocumented immigrants. Many employers hire guest workers, either because they do not have enough undocumented laborers or to justify the use of illegal labor.
\end{abstract}

\section{Keywords author:}

H-2A Visas; agriculture; guest workers; undocumented laborers; the United States.

\section{Keywords plus:}

illegal foreigners; migrant agricultural laborers; United States.

\section{La demande de travailleurs invités -travailleurs immigrants- dans l'agriculture américaine}

\section{Résumé}

Le but de cet article est celui d'examiner la raison pour laquelle la demande de travailleurs invités a augmenté dans le secteur agraire américain, dans un contexte de crise économique et de hauts taux de chômage. Une méthodologie qualitative a été utilisée et elle a inclut la réalisation, entre 2008 et 2012, d'entretiens à profondeur de 60 contrebandiers d'immigrants mexicains employés par des entrepreneurs agraires américains qui demandaient des travailleurs invités et de la main d'œuvre d'immigrants sans papiers. Le résultat le plus remarquable de cette recherche ce que la demande de travailleurs invités semble subordonnée à la disponibilité d'immigrants sans papiers. Beaucoup d'employeurs embauchent des travailleurs invités soit parce qu'ils n'ont pas des employés sans papiers suffisants ou soit parce qu'il faut justifier l'emploi de la main d'œuvre illégale.

\section{Mots-clés auteur:}

visas $\mathrm{H}-2 \mathrm{~A}$; agriculture; travailleurs invités; employés sans papiers; États-Unis

\section{Mots-clés descripteur:}

immigrés clandestins; travailleurs agricoles migrants; États-Unis 


\section{Introducción}

Con la llegada del nuevo siglo, tanto en Estados Unidos como en Europa y Asia se produjo un renovado interés por los programas de trabajadores huéspedes. El rechazo social hacia los indocumentados, que llegaron de forma masiva en las últimas décadas, contrasta con el deseo de importar de forma temporal a trabajadores no cualificados para cubrir necesidades laborales específicas, en sectores donde los empleadores no encuentran mano de obra autóctona para realizar trabajos onerosos en que los salarios y las condiciones sociolaborales son desfavorables.

En Estados Unidos el Programa $\mathrm{H}_{-2} \mathrm{~A}^{3}$ de trabajadores huéspedes ${ }^{4}$ para la agricultura fue creado en 1986 con la Ley de Reforma y Control de la Inmigración (IRCA), con objeto de permitir la contratación de mano de obra foránea a aquellos empresarios agrarios que no encontrasen trabajadores locales disponibles. En principio, solo las actividades más onerosas (las plantaciones de caña de azúcar de Florida, que empleaban a trabajadores jamaicanos, y las plantaciones de tabaco de Carolina del Norte y Virginia, que daban empleo a mexicanos) demandaron trabajadores huéspedes.

La mecanización de la caña de azúcar, a mediados de los años noventa, convirtió a México en el principal proveedor de trabajadores H-2A. La demanda de trabajadores huéspedes fue escasa durante los primeros quince años de funcionamiento del programa; a finales del siglo XX esta se incrementó, pero fue durante los últimos años cuando el Programa H-2A creció de manera más acelerada (véase el Anexo I). El incremento del número de visas $\mathrm{H}$-2 $\mathrm{A}$ implica que la agricultura estadounidense se ha tornado dependiente de los braceros mexicanos, ya que ni siquiera durante periodos de crisis económica y elevadas tasas de desempleo es capaz de atraer a la mano de obra local.

Este artículo, sustentado en los discursos de sesenta contrabandistas de migrantes empleados por empresarios agrarios, de gran parte de la geografía estadounidense, tiene como objetivo explorar las causas del reciente incremento de la demanda de

\footnotetext{
3 Los trabajadores que reciben visas $\mathrm{H}-2 \mathrm{~A}$ tienen derecho a percibir un salario igual o superior al mínimo legal; a recibir un pago mínimo equivalente a $75 \%$ de los días laborales que figuran en el contrato laboral; a obtener vivienda gratuita inspeccionada y aprobada por el Departamento de Trabajo, y a ser retribuidos por los gastos de transporte desde y hasta el lugar de origen.

4 El término "trabajadores huéspedes" designa a personas que reciben visas temporales de no inmigrantes para realizar una actividad laboral determinada para empleadores específicos; es decir, no pueden trabajar para un empleador distinto a quien les contrató. Una vez concluido el periodo temporal para el cual fueron contratados, deben regresar a su país.
} 
trabajadores huéspedes en el sector agrario de Estados Unidos. En primer lugar se describe la metodología utilizada, luego se examina el programa $\mathrm{H}-2 \mathrm{~A}$; a continuación se explica por qué los empleadores estadounidenses prefieren a los trabajadores sin documentos, más adelante se analizan los obstáculos que enfrentan los empleadores para reclutar trabajadores huéspedes y finalmente se examinan las causas del incremento del número de visas $\mathrm{H}-2 \mathrm{~A}$.

\section{Metodología}

La originalidad de este artículo radica en el diseño metodológico utilizado. Entre los meses de abril de 2008 y abril de 20 I2 fueron entrevistados sesenta contrabandistas de migrantes mexicanos, empleados por empresarios agrarios estadounidenses que contrataban o habían contratado en el pasado tanto a trabajadores $\mathrm{H}-2 \mathrm{~A}$ como a indocumentados. Cuando sus patrones carecen de mano de obra suficiente, ellos se trasladan a México para reclutar trabajadores, a quienes llevan de forma clandestina a Estados Unidos. Aunque reciben una compensación económica por su actividad como contrabandistas de migrantes, por lo general, el porcentaje mayoritario de su salario proviene del trabajo que realizan en los ranchos. El conocimiento que los entrevistados tienen de los procesos de contratación de la mano de obra les convierte en informantes valiosos para entender por qué ha crecido la demanda de trabajadores huéspedes en la agricultura estadounidense durante los últimos años.

La técnica utilizada para realizar el acopio de información fue la entrevista en profundidad. Todas las entrevistas fueron grabadas y transcritas literalmente, y el tamaño de la muestra estuvo alimentado por la riqueza heurística de la producción discursiva recabada. Cuando el número de discursos recopilados permitió explicar de forma satisfactoria por qué había crecido la demanda de trabajadores huéspedes en la agricultura estadounidense, se concluyó el trabajo de campo.

La Tabla i representa los diferentes estados donde trabajan los entrevistados. No se buscó que la muestra seleccionada representase de modo exacto la geografía donde trabajan los jornaleros participantes en el Programa H-2A. Sin embargo, algunos de los estados que más trabajadores H-2A demandan (Carolina del Norte, Florida, Texas, Virginia y Luisiana) se corresponden con los espacios donde labora la mayor parte de los entrevistados. Asimismo, los datos de esta tabla permiten inferir que la experiencia relatada por los entrevistados se refiere a la mayor parte de Estados Unidos. 
TABLA 1. Lugares donde laboran los entrevistados ${ }^{5}$

\begin{tabular}{lcclcclcc}
\hline Estado & $\mathrm{N}^{\circ}$ & $\%$ & Estado & $\mathrm{N}^{\circ}$ & $\%$ & Estado & $\mathrm{N}^{\circ}$ & $\%$ \\
\hline Texas & 24 & 40.0 & Nuevo México & 2 & 3.3 & Colorado & I & I.7 \\
\hline Carolina del Norte & I0 & I6.7 & Oklahoma & 2 & 3.3 & Georgia & I & I.7 \\
\hline Florida & 9 & 15.0 & Oregón & 2 & 3.3 & Idaho & I & I.7 \\
\hline Virginia & 5 & 8.3 & Tennessee & 2 & 3.3 & Illinois & I & I.7 \\
\hline Luisiana & 4 & 6.7 & Alabama & I & I.7 & Michigan & I & I.7 \\
\hline Arkansas & 2 & 3.3 & Arizona & I & I.7 & Minnesota & I & I.7 \\
\hline Carolina del Sur & 2 & 3.3 & California & I & I.7 & Missouri & I & I.7 \\
\hline Mississippi & 2 & 3.3 & & & & & & \\
\hline
\end{tabular}

FuENTE: elaboración propia

Por otra parte, la Tabla 2 representa la dilatada experiencia de los entrevistados, ya que habían trabajado durante una media de diez años en el reclutamiento de mano de obra para sus empleadores.

Tabla 2. Años de experiencia de los entrevistados como reclutadores de jornaleros

\begin{tabular}{llllllllllllllllllllll}
\hline Años & 3 & 5 & 6 & 7 & 8 & 9 & 10 & 11 & 12 & 14 & 15 & 16 & 17 & 18 & 19 & 21 & 22 & Total & Media \\
\hline $\mathrm{N}^{\circ}$ & $\mathrm{I}$ & 4 & 5 & $\mathrm{I} 0$ & 9 & 2 & 4 & 6 & 7 & $\mathrm{I}$ & 2 & $\mathrm{I}$ & 2 & $\mathrm{I}$ & 2 & 2 & $\mathrm{I}$ & 60 & \\
\hline$\%$ & $\mathrm{I} .7$ & 6.7 & 8.3 & 16.7 & 15.0 & 3.3 & 6.7 & 10.0 & $\mathrm{II} .7$ & $\mathrm{I} .7$ & 3.3 & $\mathrm{I} .7$ & 3.3 & $\mathrm{I} .7$ & 3.3 & 3.3 & $\mathrm{I} .7$ & 100 & \\
\hline
\end{tabular}

FuENTE: elaboración propia

\section{El programa $\mathrm{H}-2 \mathrm{~A}$}

Durante más de un siglo, los granjeros estadounidenses se han beneficiado de la disponibilidad de trabajadores migratorios; sobre esta base han realizado inversiones que no serían rentables si el flujo de migrantes se redujese (Martin y Ruhs, 20II, p. I86). Como consecuencia, el sector agrario se ha tornado dependiente de la incorporación de mano de obra foránea barata, sumisa y eficiente.

El programa de visas $\mathrm{H}-2 \mathrm{~A}$ es un esquema privado de reclutamiento de mano de obra, que protege los derechos de los empleadores y desatiende los de los inmigrantes (Durand, 2007, p. 6I). Se caracteriza por una estructura rígida que no da cabida a la organización y defensa colectiva de los jornaleros (Stephen, 2002, p. 106), quienes son apartados del contacto con organizaciones sindicales mediante campañas de intimidación (Compa, 2006, p. 48). Hill (2008, p. 315) habla de

5 Algunos de los entrevistados trabajan para empleadores que tienen ranchos en más de un estado; algunos han trabajado para empleadores de diferentes estados, y otros abastecen de indocumentados a empleadores de varios estados; por tanto, el número de lugares es superior al número de entrevistados. 
condiciones de trabajo que se aproximan a un régimen de esclavitud, y Quest (2006, p. 256) señala que los abusos cometidos contra los trabajadores $\mathrm{H}-2 \mathrm{~A}$ representan la herrumbre del sistema esclavista. Cavalieri (20II, p. 515) define las visas H-2A como una forma de tráfico de personas, porque muchos jornaleros aceptan condiciones de trabajo inhumanas para mantener sus empleos.

El aspecto más problemático de las visas $\mathrm{H}-2 \mathrm{~A}$ es que únicamente permiten al jornalero trabajar para el empleador que le contrató; si al trabajador le desagrada su situación laboral no tiene otra opción que regresar a su país con las manos vacías (Cavalieri, 20II, p. 516). Esto proporciona a los empresarios agrarios una mano de obra cautiva que no cuestiona las condiciones de trabajo ni los salarios recibidos. Con objeto de corregir esta situación se exige que los salarios de los trabajadores H-2A sean iguales o superiores al denominado "efecto adverso de la tasa salarial" (AEWR, por sus siglas en inglés). Sin embargo, el AEWR ha sido frecuentemente manipulado a mediante la imposición de umbrales de productividad (Izcara Palacios y Andrade Rubio, 20II, p. 37; Guernsey, 2007, p. 295; Smith y Ruckelshaus, 2007, p. 597). Además, la Ley de Protección de los Trabajadores Agrarios Migrantes y Estacionales (AWPA, por sus siglas en inglés) no ampara a los trabajadores $\mathrm{H}-2 \mathrm{~A}$ (Hill, 2008, p. 316), quienes tampoco perciben el seguro de desempleo. Aunque estas personas tienen derecho al Seguro de Compensación Laboral, encuentran dificultades para recibir cuidado y compensación tras un accidente laboral porque trabajan en lugares remotos, no tienen acceso al transporte y deben regresar al país de origen al expirar sus visas (Smith, 20I2, p. 542).

El programa de visas $\mathrm{H}-2 \mathrm{~A}$ no constituye un modo ideal para atender la demanda de mano de obra en el sector agrario estadounidense. Sin embargo, su crecimiento es un signo positivo porque los trabajadores indocumentados enfrentan una situación más desfavorable: ponen en riesgo su vida al cruzar la frontera de modo furtivo, se endeudan para cruzar la frontera, sufren el acoso de empleadores que les pagan salarios muy por debajo de los mínimos legales, y viven escondidos para evitar ser deportados. Estudios comparativos entre la situación laboral de los trabajadores $\mathrm{H}-2 \mathrm{~A}$ e indocumentados concluyen que los primeros presentan una menor probabilidad de recibir salarios por debajo del mínimo legal, están menos expuestos a agroquímicos (Robinson, Nguyen, Isom, Quandt, et ál., 20II, p. 264), trabajan en entornos más regulados y disfrutan de mejores condiciones sanitarias (Whalley, Grzywacz, Quandt, Vallejos et ál., 2009, p. 43I). Aunque otros estudios revelan que los jornaleros indocumentados tienen un mayor acceso a redes sociales, y más libertad para abandonar a un empleador y buscar trabajo en otro lugar (Sarathy y Casanova, 2008, p. 105). 


\section{La preferencia por los indocumentados}

La agricultura de Estados Unidos emplea de modo mayoritario a trabajadores que no tienen documentos (Carroll, Saltz y Gabbard, 2009). Un contrabandista de migrantes tamaulipeco de 34 años de edad expresaba del siguiente modo la conveniencia de emplear indocumentados: "Les pagan poco, los trabajan mucho, les cobran por ir a trabajar, porque eso es, les descuentan de su raya lo que pagaron por ellos, y además los ilegales son más chambeadores”. El empleo de indocumentados presenta cinco ventajas para los empleadores: a) son más baratos; b) trabajan más horas, más a prisa y rinden más; c) son más sumisos; d) son desechables; y e) las autoridades migratorias no persiguen a los empleadores de indocumentados.

En primer lugar, la reducción de costes de producción es el principal factor que conduce a los granjeros estadounidenses a dar empleo a inmigrantes indocumentados. En la agricultura el salario mínimo constituye un techo salarial, y en el caso de los trabajadores que no pueden acreditar su estancia legal en el país sus salarios se sitúan por debajo de los mínimos legales. Por tanto, el empleo de indocumentados incrementa de modo notable los beneficios económicos: "De ilegales te pagan por hora, y menos” (Abelardo); “Tienen que trabajar más y por menos porque sí varía el sueldo de un ilegal a un arreglado" (Adelmo); "A los ilegales les pagan menos y los trabajan más que los demás” (Casimiro); o "A ellos (los $\mathrm{H}-2 \mathrm{~A}$ ) se les paga más y a los ilegales menos y por eso emplea ilegales, por el pago" (Orlando).

Estos son testimonios que confirman a los indocumentados como una mano de obra que percibe un salario más reducido, y con una mayor exigencia laboral en comparación con los que tienen documentos. Los indocumentados, además de conformarse con salarios inferiores a los recibidos por aquellos que portan las mencionadas visas, son más agradecidos. Álvaro criticaba que los empleadores les hiciesen trabajar más que a los demás, con el argumento de que eran buenos con ellos por darles trabajo: "Se les paga menos y no es porque no tengan para pagarte, sino que también te trabajan más tiempo y tú crees, o te hacen creer, que son buenos contigo por darte trabajo sin documentos".

En segundo lugar, tan importante como el ahorro salarial derivado del empleo de indocumentados es su mayor rendimiento laboral. Los trabajadores $\mathrm{H}-2 \mathrm{~A}$ van protegidos por un contrato que les garantiza un mínimo salarial y el cobro de salarios durante su contrato; en contraste, el indocumentado debe probar su valía y rendir en el trabajo para que le den empleo: 
“Un indocumentado va a estar dispuesto a trabajar más que un arreglado, porque el que va con papeles, va seguro al trabajo, el indocumentado está probando que sabe trabajar en esto, como quien dice el ilegal trabaja más, rinde más que cualquier otro” (Adolfo).

“Un ilegal trabaja más que un contratado porque el contratado ya está seguro su sueldo y el mojado debe de ganárselo" (Gregorio).

“Los ilegales trabajan más que los que van con visa porque los de visa se confían más de que tienen trabajo seguro y los ilegales tienen que ganarse el lugar que quieren de trabajo" (Manuel).

Los entrevistados establecen una diferencia entre aquellos que tienen papeles y trabajan únicamente las horas que establecidas sus contratos, y los indocumentados, cuyas jornadas laborales no están definidas por ningún horario. Según ellos, el primer grupo rinde poco; en cambio, los segundos son percibidos como personas buenas para trabajar.

"Esos que le digo que son radicados allá, que tienen papeles, esos solo trabajan las horas que quieren [...] Esa es la diferencia por la cual quieren a la gente sin papeles, como yo, no tengo papeles, pero soy bueno para trabajar, por eso me quieren ahí” (Arturo).

"Cuando van de contratados solo trabajan el tiempo que se dice en el contrato, te digo porque ahí donde trabajamos en veces llega la compañía con su gente y ellos salen y nosotros nos quedamos a trabajar hasta después de que el sol se mete” (Celso).

"Ahí en los campos también llevan a gente a trabajar con contrato H-2A; pero ellos solo trabajan las horas que van en el contrato, y ya llevan un sueldo desde que llegan, y no trabajan más; más bien dicho no los dejan trabajar más tiempo porque van contratados” (Enrique).

"La diferencia entre un contratado, es que ese ya va contratado y que ya lleva un sueldo fijo y va asegurado y con un tiempo de trabajo, solo trabaja el tiempo que está dicho en el contrato, y un ilegal tiene que trabajar lo que le digan” (Ernesto).

El mayor rendimiento laboral de los trabajadores indocumentados suele subrayarse: 
“Como ilegal trabajas más por la necesidad y el compromiso de trabajar” (Abelardo).

"Son los que más te rinden y aun más si son de ranchos porque es gente de trabajo, no se raja” (Adán).

"Cuando se les pide trabajo por tareas, las sacan, aunque sea por las noches, y en ocasiones trabajan más de doce horas” (Agustín).

“Trabajan con más ganas que cualquier otro; ellos sí trabajan duro de sol a sol” (Ambrosio).

“Los ilegales trabajan más y rinden más que los otros” (Enrique).

“Son mejores los ilegales, trabajan más y rinden más, dan más a ganar” (Marcelo).

En algunas entrevistas se señala que muchos indocumentados ganan más que los trabajadores $\mathrm{H}-2 \mathrm{~A}$; los primeros pueden ganar hasta el doble que los últimos porque trabajan más aprisa y lo hacen durante jornadas más prolongadas.

“Un ilegal puede ganar lo doble del contratado porque el contratado solo trabaja las horas que lleva el contrato" (Enrique).

"Ganan parecido, lo que pasa es que el $\mathrm{H}-2 \mathrm{~A}$ va solo contratado por temporada y el ilegal gana por el trabajo que hace; el ilegal tiene más oportunidad de trabajo” (Erasmo).

"A los ilegales les pagan menos la hora, pero trabajan más y les pagan más por lo que hacen” (Gabriel).

“El mojado trabaja más, por consecuencia gana más dinero” (Gregorio).

En tercer lugar, otro de los aspectos por los cuales los empleadores prefieren a los indocumentados es porque son más sumisos y están dispuestos a realizar cualquier labor. Félix afirmaba: "Lo que pasa es que los H-2A solo van por temporadas, van contratados y se les vence, y tienen que venirse, y si no terminan el trabajo a ellos les vale madre, lo dejan tirado y no les importa porque van contratados”. Es decir, mientras los trabajadores $\mathrm{H}-2 \mathrm{~A}$ se dedican a cumplir el contrato que firmaron, los indocumentados hacen todo lo que se les pide. 
Los entrevistados dicen que los últimos tienen una mayor ética de trabajo, trabajan hasta terminar una tarea y evitar que se pierda la cosecha; por tanto, si su empleador les pide que prolonguen su jornada laboral lo harán: trabajarán los fines de semana o por la noche si es necesario, ya que las producciones agrarias son perecederas y el patrón podría sufrir una pérdida importante si la cosecha no se recoge a tiempo: “Trabajan más y nunca te dicen que no” (Agustín).

"Los ilegales hacen las cosas y nunca dicen que no, porque andamos dispuestos a hacer lo que se nos diga o se nos ordene, lo que queremos es trabajar, y no hay para donde se haga uno; pues por eso va para allá, a trabajar” (Casimiro).

Otro aspecto que hace que los indocumentados sean más atractivos para los empleadores que los trabajadores huéspedes es que los primeros son desechables. Los empresarios agrarios los emplean cuando su rendimiento es elevado; si se enferman o accidentan, son desechados porque dejan de ser rentables. Humberto relataba cómo su patrón dejó de contratar a trabajadores con visas $\mathrm{H}-2 \mathrm{~A}$ porque no quería responsabilizarse de sus trabajadores. Con los indocumentados, los términos del contrato entre empleador y empleado son simples: el primero no es responsable del último. Por el contrario, los trabajadores huéspedes son más problemáticos porque tienen derechos, como un jornalero mexicano que se accidentó y falleció, lo que significó grandes gastos para el patrón de Humberto.

"Llegó a emplear a cien de visa de trabajo; pero después del problema que hubo ya no empleó a nadie con visa, y el problema que tuvo fue que un chavo que iba contratado con visa de trabajo se cayó, y quedó malo, y pues, a él se lo hicieron responsable porque estaba trabajando ahí [...] y mi patrón pagó mucho dinero por él y al último el muchacho se murió [...] Dijo que jamás emplearía de estos, y lo cumplió porque no lo hace, mejor trabaja con ilegales, le rinden más que esos”.

La reticencia de los empleadores a hacerse cargo de sus trabajadores y a asumir la responsabilidad ante cualquier incidente: una enfermedad, un accidente o la pérdida de días trabajados, se destaca en las siguientes expresiones:

"A él no le gustan esos, porque es un problema contratar, además que debes estar bien, y a mi patrón no le gusta tanto lío, por eso mejor quiere puro ilegal [...] No es que esté mal, solo que salen caros, pagar seguros y todos los requisitos que les piden, y son muy exigentes y no rinden mucho en el trabajo, eso es lo que dice” (Leonardo). 
"Ahí no contratan a gente con visa $\mathrm{H}-2 \mathrm{~A}$ porque son más caros los que van con visa de trabajo, llevan su seguro y casi todo pagado, y se les paga más, y a los mojados no, se les paga menos y el patrón tiene menos problemas con ellos; vamos a decir que unos ilegales se llegaran a pelear, pues le hablas a la 'migra', y se los lleva y no hay problema, y si tuvieran visa $\mathrm{H}-2 \mathrm{~A}$ pues no los puedes correr porque tienen sus derechos que los protegen” (Esteban).

Finalmente, la Ley IRCA de I986, con objeto de detener la demanda de inmigrantes sin papeles, calificó como una violación a la ley migratoria contratar a indocumentados. Sin embargo, el riesgo que corre un empresario agrario por contratarles es muy bajo. El empleo generalizado de indocumentados en la agricultura obedece a la facilidad con que los empleadores pueden sobornar a las autoridades migratorias para que se hagan de la vista gorda ${ }^{7}$. Leonardo decía que su patrón, un empresario agrario de Carolina del Sur que años atrás contrataba trabajadores con visas $\mathrm{H}-2 \mathrm{~A}$, en la actualidad había llegado a la conclusión de que era más lucrativo sobornar a las autoridades para que le permitiesen emplear a 200 indocumentados, porque ellos recibían salarios más reducidos, eran más trabajadores y no tenían derechos. Este empleador, según Leonardo, pagaba un soborno de cien mil dólares anuales; pero lo que permite imaginar la dimensión de estos sobornos es que algunos entrevistados afirman que las autoridades migratorias estadounidenses reciben tanto o más dinero de las extorsiones que los grupos delictivos mexicanos.

Jerónimo también decía que su patrón, un empresario agrario de Arizona, dejó de emplear a cien jornaleros con visas H-2A: "Hace tiempo sí lo hacía, pero era caro el servicio, y mejor optó por solo trabajar con ilegales, de hecho hay gente de migración que le junta gente y le lleva”. Como señalaba Jerónimo las autoridades migratorias no solo le permitían a su patrón emplear trabajadores sin papeles, sino que también le vendían inmigrantes que habían capturado. Sergio, quien trabajaba para un agricultor de Virginia, también reconocía que su patrón pagaba un soborno

7 La extensión de la corrupción de los agentes migratorios estadounidenses aparece subrayada en un documento del Comité de Seguridad Nacional del Senado de ese país, donde se habla del arresto de I29 agentes migratorios desde 2003 y del temor a que más de la mitad de los nuevos agentes reclutados pudiesen ser susceptibles de corrupción (Committee on Homeland Security and Governmental Affairs, 2010). Asimismo, sobre el tema de la corrupción de los agentes migratorios estadounidenses y la aceptación de sobornos, véase Turbiville (20II) e Izcara Palacios (20I2; 20I3). 
a las autoridades migratorias; por eso dejó de solicitar trabajadores $\mathrm{H}-2 \mathrm{~A}$, aunque también le molestaba la burocracia del programa. Años atrás contrataba a 90 jornaleros con visas $\mathrm{H}-2 \mathrm{~A}$ y 120 indocumentados, ahora solo contrata jornaleros sin papeles: "Él quiere más a los ilegales porque trabajan más y les paga menos que a los contratados, y por eso ya no van contratados ahí con él, porque no los solicita, porque además que está difícil de conseguirlos, son muchos requisitos”.

\section{Los obstáculos para contratar trabajadores huéspedes}

No todos los empleadores dan preferencia a los indocumentados (Sarathy y Casanova, 2008, p. 105). Algunos empresarios agrarios únicamente contratan a trabajadores huéspedes y otros les dan preferencia a estos. Como decía Alonso, su patrón contrata de preferencia con documentos: "Pero, como le digo: si ya están allá y piden trabajo, se les da, no se les niega cuando hay trabajo". Los indocumentados no son una mano de obra segura: les pueden deportar o pueden decidir trabajar para otro empleador que les pague más. Como contraste, las personas con visa $\mathrm{H}-2 \mathrm{~A}$ solo trabajarán unos meses, pero el empleador está seguro de que durante ese periodo no buscarán empleo en otro sitio porque este tipo de visa no lo permite. Es por ello que Narciso decía que su patrón, un empresario agrario de Texas que empleaba a cien jornaleros con visas $\mathrm{H}-2 \mathrm{~A}$ y a cincuenta sin documentos, "prefiere a los que están trabajando con permisos porque no tiene problemas con ellos, pero quiere a los ilegales porque trabajan más que los contratados, y es que tiene sus ventajas trabajar con los dos".

Muchos agricultores que solicitan trabajadores con visas H-2A también contratan a indocumentados como mano de obra complementaria debido a tres obstáculos para contratar mano de obra legal: a) los jornaleros más trabajadores, demandados por los empleadores, no siempre obtienen la aprobación del Departamento de Seguridad Nacional; b) el número de trabajadores certificados por el Departamento de Trabajo es inferior al número de jornaleros requeridos por los empleadores; y c) los permisos temporales son inadecuados para resolver problemas laborales de naturaleza permanente.

La actividad agraria es muy demandante; por eso los empleadores solo quieren a los mejores trabajadores, es decir, aquellos que rinden más. Los trabajadores huéspedes son reclutados por medio de contratistas locales, que son empleados por contratistas laborales estadounidenses, y desempeñan la función de intermediarios 
entre los empresarios agrarios estadounidenses y los trabajadores. Los jornaleros más productivos son seleccionados; sin embargo, el Departamento de Seguridad Nacional es el que autoriza las visas, y no todos los elegidos cumplen los requisitos para acceder a una visa de empleo temporal ${ }^{8}$.

Cuando los trabajadores demandados por los empleadores no obtienen la aprobación para ingresar a Estados Unidos con una visa $\mathrm{H}-2 \mathrm{~A}$ son ingresados de modo clandestino por los mismos contratistas locales encargados de la gestión de los visados H-2A. Como explicaba Agustín, en ocasiones los trabajadores huéspedes y los indocumentados se mueven por los mismos canales: "El jefe [el contratista local] como es el que se encarga de los trámites de las visas $\mathrm{H}_{2} \mathrm{~A}$, cuando no pasan por causas que él no puede arreglar, él les aconseja que se vayan con él mismo, para que no pierdan, solo que los llevo yo, y pagan un poco más”.

En segundo lugar, contratar trabajadores huéspedes no es sencillo. El programa $\mathrm{H}-2 \mathrm{~A}$ condiciona la admisión de jornaleros foráneos a la inexistencia de trabajadores locales desempleados y a que no suponga un deterioro de las condiciones salariales; además, los empleadores deben demostrar que pueden proporcionarles alojamiento adecuado. El Departamento de Trabajo otorga la certificación para emplear trabajadores foráneos a aquellos empleadores que cumplen con estos requisitos; pero, en los últimos años la ratio entre trabajadores requeridos y certificados ha caído visiblemente, por lo cual muchos empleadores sufren un déficit de mano de obra (véase la Tabla 3).

TABLA 3. Ratio entre trabajadores requeridos por los empleadores y certificados por el Departamento de Trabajo

\begin{tabular}{ccccccc}
\hline A ̃̃o & 2006 & 2007 & 2008 & 2009 & 2010 & 2011 \\
\hline Ratio & 0.921 & 0.955 & 0.953 & 0.938 & 0.886 & 0.866 \\
\hline
\end{tabular}

FuENTE: Elaborado a partir de Bruno, 20I2, p. 4

Algunos empleadores que desearían contratar trabajadores huéspedes finalmente emplean indocumentados porque el Departamento de Trabajo no les autorizó contratar a trabajadores huéspedes por no cumplir con los requisitos del programa, o no les certificó tantos trabajadores como le solicitaron. Las siguientes citas

8 Algunos fueron deportados y tienen prohibido el ingreso a Estados Unidos; a otros les deniegan las visas por considerar que existe un riesgo de que permanezcan en el país después de que estas expiren. 
hacen referencia a la necesidad que tienen muchos empleadores de recurrir a los indocumentados debido al insuficiente número de trabajadores $\mathrm{H}-2 \mathrm{~A}$ autorizados.

"La gente no le da muchos contratados, y por eso se ve en la necesidad de emplear a gente ilegal” (Francisco).

"Antes iban a trabajar y les llevaban a mi patrón; pero desde un tiempo acá ya no van, ya no le quisieron dar, y por eso hace esto de llevar gente ilegal desde México" (Gerardo).

"De H-2A ocupa una cuadrilla, es lo más que ocupa, y también no le dan a muchos contratados, por eso ocupa ilegales” (Gregorio).

"No les dan a muchos el beneficio de contratar a gente con visa de trabajo, solo son contados” (Ignacio).

"Para que le den contratados también batalla porque hay muchos agricultores que los contratan y a los que contratan más les dan preferencia” (Sancho).

"No es que solo quieran gente ilegal; solo que es la que hay, y ellos la tienen que tomar para no perder la cosecha” (Alberto).

Finalmente, Castles (2006, p. 759) ha señalado que los programas de trabajadores huéspedes estacionales y muy restrictivos resultan insuficientes porque operan por medio de permisos temporales para resolver problemas laborales de naturaleza permanente. En este sentido, los entrevistados hacen referencia a la inadecuación del lapso que permanecen los trabajadores huéspedes en Estados Unidos con las necesidades laborales de los empleadores. Estos dicen que sus patrones deben contratar indocumentados porque cuando a los trabajadores huéspedes se les acaba el contrato deben regresar a su país y dejan el trabajo sin terminar.

"Ahí llegan contratados por temporadas; pero solo trabajan las temporadas que llevan de permiso y se regresan a que los vuelvan a mandar, y eso a veces es tardado, por eso mi patrón ocupa a ilegales, para que trabajen, porque los de visa no son muy seguros porque como están por tiempos de contrato y luego se los traen al permiso otra vez, y pues, qué tanto son seis meses los que están allá, no son nada” (Sancho). 


\section{Las causas del incremento de la demanda de trabajadores huéspedes}

El incremento de la demanda de trabajadores huéspedes en la agricultura resulta paradójico porque ha coincidido con un periodo de crisis económica e incremento de las tasas de desempleo. Dos factores ayudan a explicar este hecho: a) la reducción del número de indocumentados disponibles debido a una disminución de los cruces subrepticios y a un incremento de las deportaciones; y b) la contratación de trabajadores con visas $\mathrm{H}-2 \mathrm{~A}$ para justificar el empleo de indocumentados.

Entre los años 2000 y 201 el número de inmigrantes aprehendidos por la Patrulla Fronteriza al intentar traspasar la frontera ha caído más de $80 \%$, es decir, de I 675876 a 323542 personas. Por otro lado, el número de expulsiones con una orden de deportación se ha duplicado: de I88 467 a 391953 personas (Department of Homeland Security, 2012). La drástica reducción del número de migrantes que se atreven a entrar de modo ilegal a Estados Unidos, unida a un incremento de las deportaciones ha generado un déficit de mano de obra en la agricultura.

Como explicaba Benjamín, cada día es más difícil encontrar indocumentados; los jornaleros mexicanos ya no quieren emigrar a Estados Unidos, en parte debido al incremento de las deportaciones, pero principalmente por la violencia que se ha esparcido en los territorios fronterizos mexicanos. Una década atrás los indocumentados constituían una mercancía abundante, la cantidad de jornaleros que se acercaba a los ranchos en búsqueda de empleo era superior al número de brazos requeridos; como contraste, en la actualidad estos se han convertido en una mercancía escasa, los empleadores buscan retener el mayor tiempo posible a los indocumentados que trabajan en sus ranchos y cada vez es más difícil reponer a aquellos que se van: "Yo era quien buscaba gente ilegal para llevarlos a trabajar al rancho; cada día está más difícil encontrarlos [...] el que se encuentra uno o más los conservan para que no se les vayan".

La dificultad para abastecerse de indocumentados ha conducido a muchos empleadores a contratar trabajadores con visas $\mathrm{H}-2 \mathrm{~A}$ para sustituir aquellos puestos que dejaron vacantes quienes regresaron de forma voluntaria a su país o fueron deportados. Como decía Narciso: "Sí están contratando a más personas con $\mathrm{H}_{2} \mathrm{~A}$ porque está dura la migración y hay más deportaciones, y ahí es donde pierden ellos porque los trabajadores que agarran les hacen falta a ellos para trabajar”.

Los trabajadores huéspedes son contratados en muchas ocasiones como sustitutos de los indocumentados. Cuando un empleador carece de mano de obra 
indocumentada suficiente emplea trabajadores huéspedes. Como se refleja en las siguientes citas, algunos empleadores solo contratan trabajadores huéspedes de modo ocasional, cuando las necesidades laborales son muy elevadas.

"No siempre emplea, ni en cada temporada, solo ocasionalmente, cuando faltan ilegales, mete y manda pedir de contrato" (Gabriel).

"Él pide lo que ocupa; pero siempre le da preferencia a los ilegales porque estos siempre están dispuestos a trabajar, hasta en la noche si es necesario" (Juan).

"En las huertas sí los ocupa para los cortes fuertes, no siempre tiene, solo cuando los necesita los manda pedir y van a trabajarle” (Luciano).

Por otra parte, otros empleadores contratan a trabajadores con visas $\mathrm{H}-2 \mathrm{~A}$ para contentar o engañar a las autoridades migratorias. Algunos entrevistados decían que las autoridades exigían a los empleadores que contratasen a algunos trabajadores legales para poder justificar tras las inspecciones en los lugares de trabajo que no violaban la ley migratoria; otros decían que con las visas $\mathrm{H}-2 \mathrm{~A}$ los empleadores engañaban o despistaban a las autoridades.

"Antes había dejado de ocupar mi patrón, solo que los necesita para poder justificar los ilegales y volvió a pedir; no le permiten tener solo ilegales” (Marcelo).

“El patrón está arreglado así de esta manera para que lo dejen trabajar y no lo molesten; al trabajo no entra migración a buscar ilegales porque él, mi patrón, ya está arreglado y él presenta el papel donde está trabajando con contratados, por eso también contrata a personas de trabajo temporal” (Sancho).

"Los mojados tienen más valor para él, ahora ya tiene como dos años que no manda pedir con visa de trabajo, antes solo pedía pocos, solo para despistar, pero ya no pidió porque lejos de ganar pierde con ellos” (Manuel).

\section{Conclusiones}

Los agricultores estadounidenses siempre han buscado mano de obra barata y esforzada, que acepta en silencio condiciones sociolaborales rechazadas por los 
locales. El programa H-2A se creó en 1986 para prevenir una situación de escasez de mano de obra agraria. Sin embargo, el creciente flujo de indocumentados permitió que los empleadores pudiesen abastecerse de la miríada de migrantes que llegaban hasta los ranchos; como consecuencia, a pesar del rechazo de la mano de obra local hacia el empleo agrario, el número de trabajadores huéspedes reclutados fue bajo.

Como contraste, a partir de 2007 el flujo de indocumentados colapsó. Año con año el número de migrantes que atravesaban la frontera de modo subrepticio se contrajo, y la demanda de indocumentados se elevó por encima de la oferta. La alternativa más rentable al empleo de indocumentados fue el reclutamiento de trabajadores huéspedes. Por otra parte, el crecimiento de un sentimiento antiinmigración condujo a un mayor escrutinio de los lugares de trabajo. En este contexto, las visas $\mathrm{H}-2 \mathrm{~A}$ se utilizaron para dar un barniz de legalidad a un sector caracterizado por la irregularidad. De este modo los empleadores aparentan que se apegan a la legalidad y las autoridades simulan que son estrictas y luchan por combatir el empleo de inmigrantes indocumentados.

En conclusión, el crecimiento del número de trabajadores huéspedes en la agricultura estadounidense no obedece a un proceso de regularización de la mano de obra empleada en este sector, sino a la adaptación a una coyuntura que ha detenido el flujo de indocumentados y que ha conducido a algunos empleadores a contratar trabajadores huéspedes para no tener que desprenderse de aquellos más productivos: los indocumentados. Estos continúan representando el grueso de la mano de obra asalariada agraria porque los patronos conservan su preferencia por los jornaleros sin papeles.

\section{Referencias}

Bruno, A. (2012). Immigration of Temporary Lower-Skilled Workers: Current Policy and related Issues. Congressional Research Service. Report for Congress. Recuperado el I5 de diciembre de 2012, de http://www.fas.org/sgp/crs/homesec/ R42434.pdf

Carroll, D., Saltz, R. y Gabbard, S. (2009). The Changing Farm Workforce: Findings from the National Agricultural Workers Survey. Immigration Reform and Agriculture Conference: Implications for Farmers, Farm Workers, and Communities. University of California. Recuperado el I2 de marzo de 20I4, de http://migrationfiles.ucdavis.edu/uploads/cf/files/2009-may/carroll-saltznaws.pdf 
Castles, S. (2006). Guestworkers in Europe: A Resurrection? International Migration Review, 40(4), 74I-766.

Cavalieri, S. (20II). The Eyes that Blind Us: the Overlooked Phenomenon of Trafficking into the Agricultural Sector. Northern Illinois University Law Review, 3I, 50I-5I9.

Committee on Homeland Security and Governmental Affairs (2010). New Border War: Corruption of US Officials by Drug Cartels. Hearing Before the ad hoc Subcommittee on State, Local and Private Sector Preparedness and Integration of the Committee on Homeland Security and Governmental Affairs United States Senate. Washington D.C.: US Government Printing Office. Recuperado el Io de enero de 20I2, de http://www.hsdl.org/?view\&did=I4472

Compa, L. (2006). Workers' Freedom of Association in the United States: the Gap between Ideals and Practice. En J. Gross, Workers' Rights as Human Rights (pp. 23-I06). Ithaca: Cornell University Press.

Department of Homeland Security (20I2). $201 \mathrm{I}$ Yearbook of Immigration Statistics. Recuperado el 20 de marzo de 20I2, de http://www.dhs.gov/sites/default/files/ publications/immigration-statistics/yearbook/20II/ois_yb_20II.pdf

Durand, J. (2007). Programas de trabajadores temporales. Evaluación y análisis del caso mexicano. México D. F.: Consejo Nacional de Población.

General Accounting Office [GAO] (1997). H-2A Agricultural Guestworker Program. Changes Could Improve Services to Employers and Better Protect Workers. United States General Accounting Office Report to Congressional Committees (GAO/T-HEHS-98-20).

Guernsey, A. (2007). Double Denial: How Both the DOL and Organized Labor Fail Domestic Agricultural Workers in the Face of H-2A. Iowa Law Review, 93(I), 277-323.

Hill, J. (2008). Binational Guestworker Unions: Moving Guestworkers into the House of Labor. Fordham Urban Law Journal, 35, 307-338.

Izcara Palacios, S. P. (20I2). Coyotaje y grupos delictivos en Tamaulipas. Latin American Research Review, 47(3), 4I-6I.

Izcara Palacios, S. P. (2013). Corrupción y contrabando de migrantes en Estados Unidos. Política y Gobierno, 20(I), 79-I06.

Izcara Palacios, S. P. y Andrade Rubio, K. (20II). Guest Workers’ Working Conditions in U.S. Farming: The Example of Farm Workers from Tamaulipas. Journal of Workplace Rights, I5(I), 27-46. 
Martin, P. y Ruhs, M. (20II). Labor Shortages and US Immigration Reform: Promises and Perils of an Independent Commission. International Migration Review, 45(I), 179-192.

Quest, B. (2006). Process Theory and Emerging Thirteenth Amendment Jurisprudente: The Case of Agricultural Guestworkers. University of San Francisco Law Review, 4I, 233-260.

Robinson, E., Nguyen, H., Isom, S., Quandt, S., Grzywacz, J., Chen, H. y Arcury, T. (20II). Wages, Wage Violations and Pesticide Safety Experienced by Migrant Farmworkers in North Carolina. New Solutions, 22(2), 251-268.

Sarathy, B. y Casanova, V. (2008). Guest Workers or Unauthorized Immigrants? The Case of Forest Workers in the United States. Policy Sciences, 4I(2), 95-II4.

Smith, R. y Ruckelshaus, C. (2007). Solutions, not Spacegoats: Abating Sweatshop Conditions for all Low-wage Workers as a Centerpiece of Immigration Reform. Legislation and Public Policy, $10,555-602$.

Smith, R. (2012). Immigrant Workers and Worker's Compensation: The Need for Reform. American Journal of Industrial Medicine, 55(6), 537-544.

Turbiville, G. (20II). Silver over the Border: US Law Enforcement Corruption on the Southwest Border. Small Wars Eo Insurgencies, 22 (5), 835-859.

Whalley, L., Grzywacz, J., Quandt, S., Vallejos, Q., Walkup, M., Chen, H., Galvan, L. y Arcury, T. (2009). Migrant Farmworker Field and Camp Safety and Sanitation in Eastern North Carolina. Journal of Agromedicine, I4(4), 42I-436. 


\section{Anexo I}

Trabajadores participantes en el Programa H-2A

\begin{tabular}{|c|c|c|c|c|c|c|c|c|c|c|c|}
\hline AÑo & DOL & DOS & DHS & AÑ̃o & DOL & DOS & DHS & AÑo & $\mathrm{DOL}$ & DOS & DHS \\
\hline I986 & --- & --- & --- & I995 & I2 862 & 8379 & II 394 & 2004 & 44619 & 31774 & 22 I4I \\
\hline 1987 & $\mathrm{I} 3 \mathrm{II} 3$ & --- & --- & I996 & 15235 & II $\bigcirc 04$ & 9635 & 2005 & 48366 & 31 892 & 7011 \\
\hline I988 & I6 782 & --- & --- & 1997 & 23297 & I6 OII & --- & 2006 & 59 I10 & 37 I49 & 46432 \\
\hline 1989 & I7 6I4 & --- & --- & I998 & 22676 & 22676 & 27308 & 2007 & 76814 & $5079 \mathrm{I}$ & 87316 \\
\hline 1990 & I9 199 & --- & I8 219 & I999 & 28568 & 28568 & 32372 & 2008 & 82099 & 64404 & 173103 \\
\hline I99I & I8 273 & --- & I8 440 & 2000 & 30201 & 30201 & 33292 & 2009 & 86 OI4 & 60 II2 & I 49763 \\
\hline 1992 & I4 798 & 6445 & I6 390 & $200 \mathrm{I}$ & 31523 & 31523 & 27695 & 2010 & 79 OII & $5592 \mathrm{I}$ & 139406 \\
\hline 1993 & 13342 & 7243 & I4 628 & 2002 & 31538 & 31538 & I5 628 & 2011 & $68 \circ 88$ & 55384 & I884II \\
\hline I994 & $\mathrm{I} 34 \mathrm{I} 8$ & $772 \mathrm{I}$ & 13185 & 2003 & 44033 & 29882 & I4 O94 & & & & \\
\hline
\end{tabular}

El Departamento de Trabajo (DOL) recoge el número de trabajadores certificados.

El Departamento de Estado (DOS) recoge el número de visas H-2A expedidas.

El Departamento de Seguridad Nacional (DHS) recoge el número de entradas a Estados Unidos con una visa H-2A (registra las entradas múltiples).

FuENTE: elaboración propia a partir de: GAO, 1997, pp. 100 y 10I; Bruno, 2012, pp. 4 y 30; US Department of Homeland Security, Yearbook of Immigration Statistics (varios años) 


\begin{tabular}{|c|c|}
\hline \multicolumn{2}{|c|}{ Entrevistas Citadas en el Texto $(*)$} \\
\hline Abel & Contrabandista de migrantes de Tamaulipas, de 34 años de edad \\
\hline Abelardo & Contrabandista de migrantes de Tamaulipas, de 38 años de edad \\
\hline Adán & Contrabandista de migrantes de Tamaulipas, de 39 años de edad \\
\hline Adelmo & Contrabandista de migrantes de Tamaulipas, de 30 años de edad \\
\hline Adolfo & Contrabandista de migrantes de Tamaulipas, de 34 años de edad \\
\hline Agustín & Contrabandista de migrantes de Tamaulipas, de 42 años de edad \\
\hline Alberto & Contrabandista de migrantes de Tamaulipas, de 40 años de edad \\
\hline Alonso & Contrabandista de migrantes de Tamaulipas, de 45 años de edad \\
\hline Alvaro & Contrabandista de migrantes de Tamaulipas, de 45 años de edad \\
\hline Ambrosio & Contrabandista de migrantes de Tamaulipas, de 33 años de edad \\
\hline Arturo & Contrabandista de migrantes de Tamaulipas, de 35 años de edad \\
\hline Benjamín & Contrabandista de migrantes de Texas, de $4 \mathrm{I}$ años de edad \\
\hline Casimiro & Contrabandista de migrantes de Tamaulipas, de 33 años de edad \\
\hline Celso & Contrabandista de migrantes de Nuevo León, de 40 años de edad \\
\hline Enrique & Contrabandista de migrantes de Tamaulipas, de 39 años de edad \\
\hline Erasmo & Contrabandista de migrantes de Tamaulipas, de 38 años de edad \\
\hline Ernesto & Contrabandista de migrantes de Tamaulipas, de 45 años de edad \\
\hline Esteban & Contrabandista de migrantes de Tamaulipas, de 35 años de edad \\
\hline Félix & Contrabandista de migrantes de Veracruz, de 39 años de edad \\
\hline Francisco & Contrabandista de migrantes de Tamaulipas, de 33 años de edad \\
\hline Gabriel & Contrabandista de migrantes de Tamaulipas, de 46 años de edad \\
\hline Gerardo & Contrabandista de migrantes de México D.F., de 45 años de edad \\
\hline Gregorio & Contrabandista de migrantes de Tamaulipas, de 43 años de edad \\
\hline Humberto & Contrabandista de migrantes de Tamaulipas, de 2I años de edad \\
\hline Ignacio & Contrabandista de migrantes de San Luis Potosí, de 37 años de edad \\
\hline Jerónimo & Contrabandista de migrantes de San Luis Potosí, de 30 años de edad \\
\hline Juan & Contrabandista de migrantes de Chiapas, de 39 años de edad \\
\hline Leonardo & Contrabandista de migrantes de Tamaulipas, de 29 años de edad \\
\hline Luciano & Contrabandista de migrantes de San Luis Potosí, de 45 años de edad \\
\hline Manuel & Contrabandista de migrantes de Tamaulipas, de 36 años de edad \\
\hline Marcelo & Contrabandista de migrantes de Tamaulipas, de 40 años de edad \\
\hline Narciso & Contrabandista de migrantes de Coahuila, de 4I años de edad \\
\hline Orlando & Contrabandista de migrantes de Tamaulipas, de 45 años de edad \\
\hline Sancho & Contrabandista de migrantes de Tamaulipas, de 48 años de edad \\
\hline Sergio & Contrabandista de migrantes de Coahuila, de 40 años de edad \\
\hline$(*) \operatorname{Los}$ nom & s son pseudónimos \\
\hline
\end{tabular}

Fuente: elaboración propia 